\title{
Obscure gastrointestinal bleeding caused by congenital enteropathy in a Chinese young child-a case report
}

\author{
Youhong Fang ${ }^{1}$, Weizhong $\mathrm{Gu}^{2}$, Youyou Luo ${ }^{1}$ and Jie Chen ${ }^{1 *}$ (D)
}

\begin{abstract}
Background: SLCO2A1 was recently reported to cause nonspecific ulcers at small bowel, it was named as chronic enteropathy associated with SLCO2A1 (CEAS). It was rarely reported beyond the Japanese population.

Case presentation: A 4-year-5-month old girl presented with intractable anemia since 1-year-3-month. Her stool occult blood test was positive and the result of esophagogastroduodenoscopy and colonoscopy were normal. She was considered as obscure gastrointestinal bleeding. The magnetic resonance enterography and ultrasound of small intestinal revealed segmental thickening of small bowel. The capsule endoscopy detected ulcers, erosion and slightly stenosis near the site of junction of jejunum and ileum. She was considered chronic non-specific multiple ulcers of the small intestine and was advised to have whole exon sequencing. She was treated with exclusive enteral nutrition and iron supplement for two months. However, she was not responsive to this treatment, then she had three doses of infliximab. At the same time, the next-generation sequencing of this patient revealed two novel compound heterozygous mutations in SLCO2A1. She was diagnosed with CEAS and was treated with oral mercaptopurine. Her hemoglobin level was stable and the serum albumin level was slightly decreased during the follow up.
\end{abstract}

Conclusion: CEAS may present as nonspecific small bowel ulcers, and misinterpret as small bowel Crohn's disease. Genetic tests may help with the precise diagnosis of small bowel ulcers.

Keyword: Anemia, SLCO2A1, CEAS, Obscure gastrointestinal bleeding, Small bowel ulcer

\section{Background}

Obscure gastrointestinal bleeding is defined as bleeding of unknown origin that persists or recurs, after negative initial evaluation using upper and lower endoscopy and radiologic small bowel imaging [1]. The etiology of OGIB including inflammation, small vascular malformations, and polyps et al. Recently, a new gene SLCO2A1 encodes a prostaglandin transporter was reported to cause small bowel nonspecific ulcers and sometimes cause stricture of small bowel which named as chronic

\footnotetext{
* Correspondence: 6185020@zju.edu.cn

'Department of Gastroenterology, The Children's Hospital, Zhejiang

University School of Medicine, National Clinical Research Center for Child Health, 3333 Bin Sheng RoadZhejiang Province, Hangzhou 310052, China Full list of author information is available at the end of the article
}

enteropathy associated with SLCO2A1 (CEAS). The main presentation of CEAS reported was anemia. To date, most of the cases reported about this disease were from Japanese population. Here we report a case of Chinese young girl who presented with chronic anemia due to OGIB and finally diagnosed as CEAS.

\section{Case presentation}

A 4-year-5-month old girl was referred to our ward with complaint of anemia for more than three years. She was detected iron deficiency anemia at one year and three months old. She had no dizziness, no cough, no fatigue, no hematuria, no abdominal pain, no melena or bloody stool. Her appetite and normal nutritional status were normal. She was the first child in her family, and her 
parents and sister didn't have anemia. Her blood routine test showed the hemoglobin level was $96 \mathrm{~g} / \mathrm{L}$, mean corpuscular volume (MCV) was $79.9 \mathrm{fL}$, mean corpuscular hemoglobin $(\mathrm{MCH})$ was $24.9 \mathrm{pg}$, mean corpuscular hemoglobin concentration was $(\mathrm{MCHC}) 312 \mathrm{~g} / \mathrm{L}$, which indicated a hypochromic microcytic anemia. She was referred to the hematologist, and the results of etiology tests for anemia were showed in the Table 1. High resolution melting did not detect hot mutations of thalassemia and the bone marrow morphology test revealed hypochromic microcytic anemia. During the three years, she accepted iron supplementation intermittently. Her hemoglobin level was ranging from 67 to $120 \mathrm{~g} / \mathrm{L}$.

She was referred to a gastroenterologist because the stool occult blood test was positive sometimes. She had no history of taking aspirin or any other medicine. Her serum albumin level was $34 \mathrm{~g} / \mathrm{L}$. She was diagnosed with gastrointestinal bleeding, and started the initial laboratory tests (Table 1). The EGD and the colonoscopy

Table 1 The results of laboratory tests of the patient

\begin{tabular}{ll}
\hline Laboratory tests & Results \\
\hline The percentage of reticulocytes & $0.8 \%-7 \%(0.5-1.5 \%)$ \\
Serum iron level & $2.9-9.6 \mu \mathrm{ml} / \mathrm{L}(8.9-32.3 \mu \mathrm{ml} / \mathrm{L})$ \\
Serum ferritin level & $2.0-6.2 \mu \mathrm{g} / \mathrm{L}(11-306 \mu \mathrm{ml} / \mathrm{L})$ \\
Serum total iron binding capacity & $48.5-64.7 \mu \mathrm{mol} / \mathrm{L}(54-77 \mu \mathrm{mol} / \mathrm{L})$ \\
Glucose-6-phosphate dehydrogenase & $44.8 \mathrm{U} / \mathrm{dL}(>26 \mathrm{U} / \mathrm{dL})$ \\
Serum levels of vitamin B12 & $760(180-914) \mathrm{pg} / \mathrm{ml}$ \\
Serum levels of folic acid & $11.2(3.1-20.5) \mathrm{ng} / \mathrm{ml}$ \\
Direct and indirect Coomb's tests & Negative \\
Hemoglobin electrophoresis & Normal \\
Erythrocyte sedimentation rate & $11(0-20) \mathrm{mm} / \mathrm{h}$ \\
C-reactive protein & $<0.5 \mathrm{mg} / \mathrm{L}$ \\
Serum albumin & $29.9-40.9(32-52) \mathrm{g} / \mathrm{L}$ \\
Fecal calprotectin & $>1800(<200 \mathrm{ng} / \mathrm{g})$ \\
Serum immunoglobin levels & \\
Ig G & $5.6(5-10.6) \mathrm{g} / \mathrm{L}$ \\
Ig M & $1.31(0.44-1.44) \mathrm{g} / \mathrm{L}$ \\
Ig A & $1.12(0.32-1.38) \mathrm{g} / \mathrm{L}$ \\
Ig E & $<18.9(0-100) \mathrm{IU} / \mathrm{ml}$ \\
Subsets of T cells & \\
CD19 & Negative \\
CD3 & Neg.65 $(21-33) \%$ \\
CD4/CD8 & $61.60(60-71) \%$ \\
Antibodies of Epstein-barr virus & Negative \\
Antibodies of Cytomegalovirus & Negative \\
Interferon Gamma Release Assays & \\
Antinuclear antibodies & Antineutrophil antibody
\end{tabular}

didn't detect ulcer or inflammation. The results of magnetic resonance enterography (MRE) and the ultrasound revealed segmental thickening of small intestinal wall, with the wall thickness of $0.46 \mathrm{~cm}$ and mainly involved the mucosal and submucosal of small intestinal. Capsule endoscopy didn't reach the terminal ileum during the working time and a retention was observed. It revealed superficial ulcers and erosion at the location of stricture near the junction of jejunum and ileum (Fig. 1). She had double balloon endoscopy (DBE) through both mouth and anus. However, the DBE didn't reach the location of stricture, and it did not reveal any other lesions. Based on the small bowel ulcers and stricture, anemia, mild hypoalbuminemia, and obviously increased fecal calprotectin, she was initially diagnosed as chronic non-specific multiple ulcers of the small intestine (CNSU) and very early onset small bowel intestinal Crohn's disease was the main differential diagnosis. She was advised to have whole exome sequencing because of early disease onset and suspecting congenital disease. She was treated with exclusive enteral nutrition (EEN) and iron supplement after discussing with her parents.

She received EEN and iron supplement for eight weeks. The hemoglobin level was ranging between 90 and $107 \mathrm{~g} / \mathrm{L}$, and the repeated fecal calprotectin was still higher than $1800 \mathrm{ng} / \mathrm{g}$. She received infliximab. However, she still had anemia and hypoalbuminemia after three doses of infliximab.

\section{Genetic analysis}

The next generation sequencing revealed two novel compound heterozygous mutations in SLCO2A1: chr3133,654,624, c.1808G > C (p.R603P), chr3-133,654,616, c.1814 + $2 \mathrm{~T}>\mathrm{G}$ (splice-5). The two variants were confirmed by sanger sequencing, and were derived from her mother and father, separately (Fig. 2). Her sister didn't carry the variants.

\section{Immunohistochemical analysis of SLCO2A1 protein}

SLCO2A1 expressions in the duodenal tissues were positive in patient and control (Fig. 3). The control with the complaint of intermitted abdominal pain for one year, and finally diagnosed with primary dysmenorrhea. CD31 immunostaining indicated the vascular endothelial cells of the capillary vessels in the mucosa of patient and control.

\section{Follow up}

SLCO2A1 mutation is related to the chronic nonspecific multiple ulcers of the small intestine. Combined with her history and character of her endoscopy findings, she was diagnosed as CEAS. There was no effective treatment according to the reported literatures about the treatment for CEAS. Some patients were responsive to 

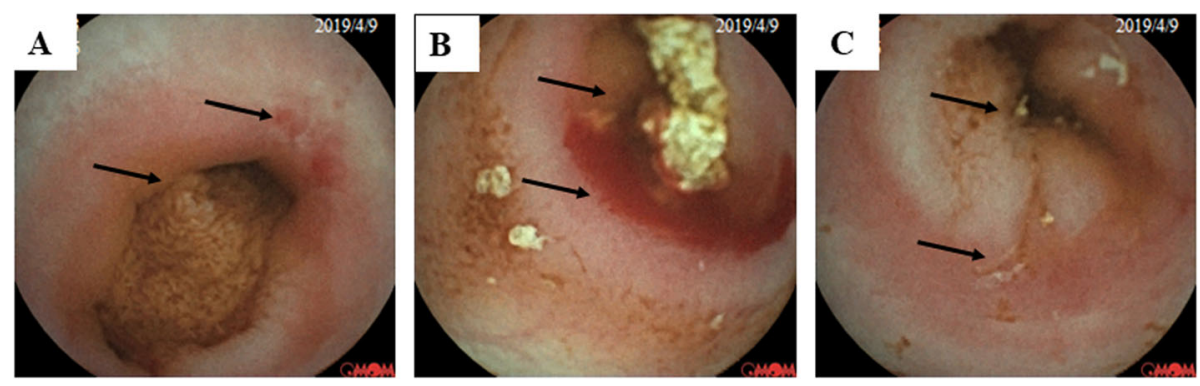

Fig. 1 The capsule endoscopy revealed stricture, superficial ulcers and erosion in the small intestinal near the junction of jejunum and ileum

the immunosuppressants, but were not responsive to the biological agents. She switched to mercaptopurine with the dose of $1 \mathrm{mg} / \mathrm{kg}$ per day. Up to the latest follow up, she didn't have any abdominal symptoms and her hemoglobin level was increased from $76 \mathrm{~g} / \mathrm{L}$ to $98 \mathrm{~g} / \mathrm{L}$, the serum albumin level was a bit decreased.

\section{Discussion and Conclusion}

OGIB can be caused by small bowel ulcers, the ulcers can be interpreted as mucosal inflammation, vasculitis, druginduced or nonspecific ulcers caused by inherited diseases. With the exploration to the last terminal of small intestinal by using of DBE and CE, increasing small intestinal diseases were recognized, among them there was a group of diseases presenting as nonspecific multiple ulcers in the small intestinal. It is identified with mutation of gene $S L C O 2 A 1$ and is also called CEAS [2].

We searched the keywords of "CEAS", "nonspecific multiple ulcers" or "SLCO2A1 and enteropathy" in the PUBMED and reviewed the literatures. So far as we know, all of the patients reported in the literatures diagnosed with CEAS were almost Japanese, except two patients recently reported by Korea [3] and Chinese [4]. Thus, we hypothesized that CEAS was underestimated or was not recognized in Chines patients. In this study, we reported a young child presented with OGIB caused by compound heterozygous mutations of SLCO2A1. This young child was mainly presented with anemia, and

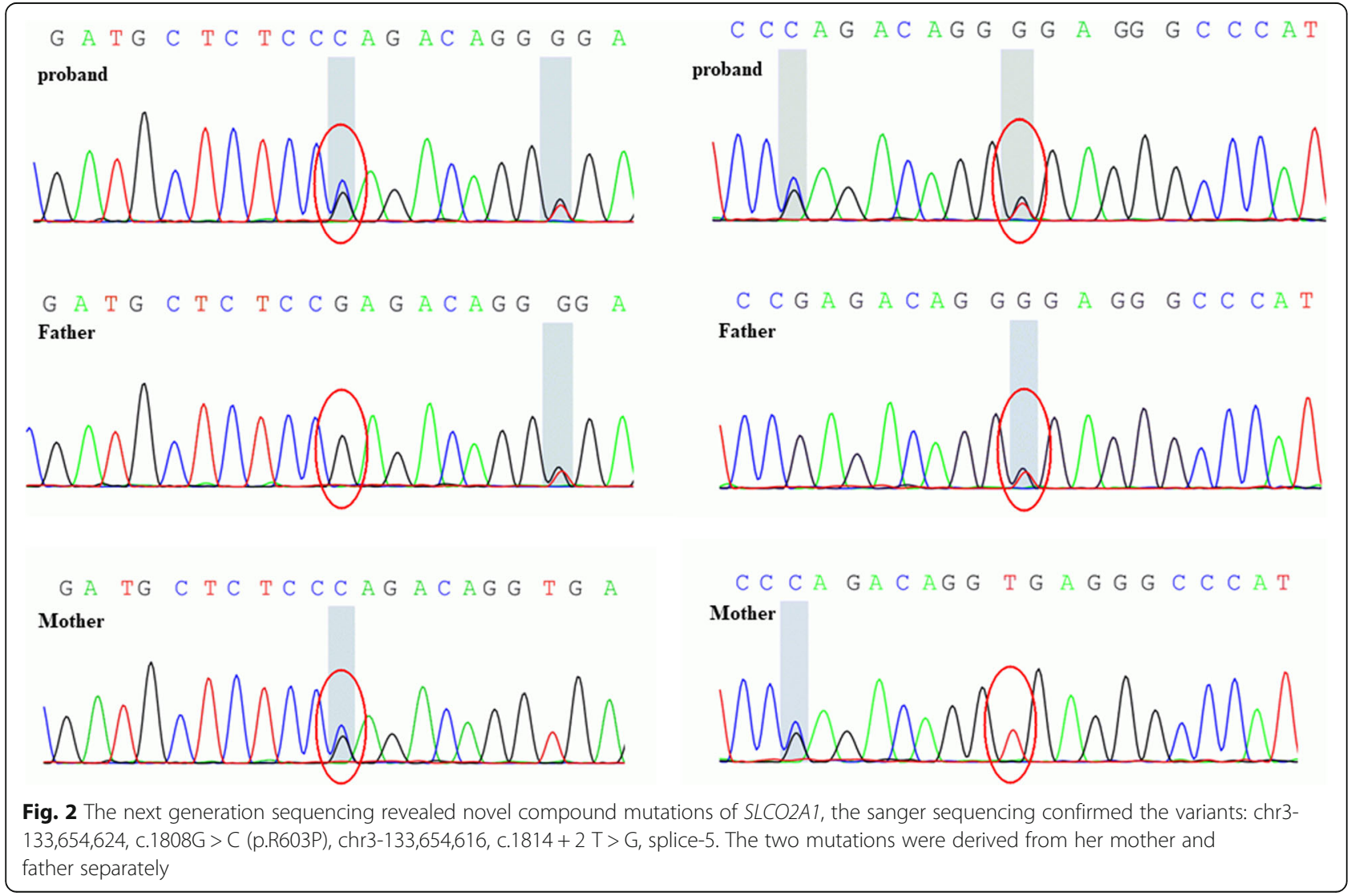




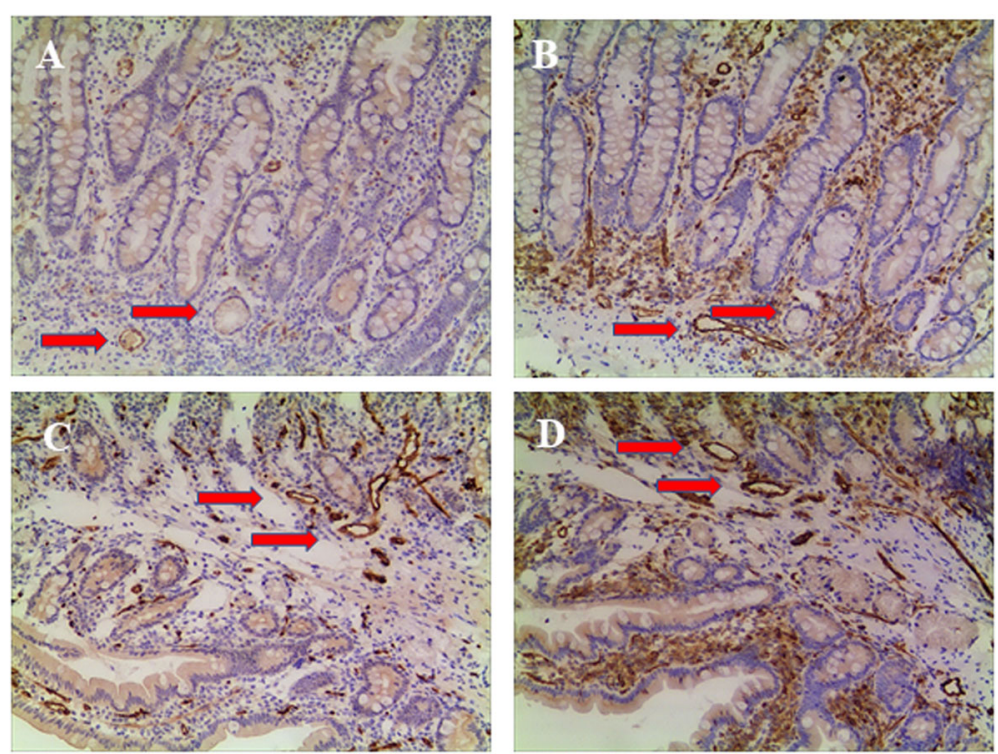

Fig. 3 SLCO2A1 immunostaining. The duodenal tissue obtained by endoscopic biopsy from both of the patient $(A \times 100)$ and control $(C \times 100)$ were positive. CD31 immunostaining indicated the vascular endothelial cells of the capillary vessels in the mucosa of patient $(B \times 100)$ and control $(\mathrm{D} \times 100)$

detected small bowel ulcers, erosion and stricture by capsule endoscopy.

A national study in Japan [5] including 65 CEAS patients identified 46 patients with SLCO2A1 mutations at 11 sites. This disease predominantly occurs in woman, the male vs female ratio was $1: 2.5$, and it tends to affect the adolescents, with disease onset at 16.5 years (range, 1-69 years). There was only one literature focused on the child onset CEAS which reported four cases of CEAS children, and two patients were have disease onset within 2 years old [6]. The clinical features of these patients were mainly anemia 45 (98\%), abdominal pain 18 (39\%) and edema 11 (24\%) [5]. CEAS ulcers are characterized by multiple, circular or eccentric oblique, shallow lesions with discrete margins [7]. In all the CEAS patients, the ileum is most frequently involved (98\%-100\%) [5], and the terminal ileum is not involved. While for small bowel Crohn's disease, terminal ileum is the most common frequently involved. Patients with SLCO2A1 mutation has negative immunohistochemical staining for SLCO2A1 while the patient reported here was positive. The immunohistochemical staining is useful in the diagnosis of CEAS. However, patients with deleterious mutations of $S L C O 2 A 1$ but not truncated mutation could not detect by immunohistochemical study [8]. Our patient may have the same condition.

There were several hot mutations reported in the Japanese population. Among the detected SLCO2A1 mutations, a splicing mutation at intron 7 (c. $940+$ $1 \mathrm{G}>\mathrm{A}$; rs765249238) was the most frequently observed among CEAS patients, with $54 \%$ of mutation allele frequency [5]. Our patient had disease onset as early as one year and three months, and harbored two novel mutations, which were not reported in Japanese population. Mutation of c.1808 g $>$ C, resulting amino acid changes from arginine to proline, the frequency of this mutation is 0.000024 among the normal population. Mutation of c. $1814+2 \mathrm{~T}>\mathrm{G}$, causes splicing mutation at terminal 5 which resulting amino acid change. According to the American College of Medical Genetics and Genomics the variant of c.1808 $\mathrm{g}>\mathrm{C}$ was identified as variants of unknown significance and the variant of c.1814 $+2 \mathrm{~T}>\mathrm{G}$ was identified as Likely Pathogenic. The hot mutations in different genetic background maybe different.

$S L C O 2 A 1$ is also identified as a causal gene of primary hypertrophic osteoarthropathy (PHO) in 2012 [9]. Since then, many $\mathrm{PHO}$ patients were reported to have mutations of SLCO2A1 [10-12]. Interestingly, among the PHO patients with SLCO2A1 mutations over $50 \%$ percent patients had watery diarrhea and over $20 \%$ patients had anemia [13]. Unfortunately, there were no reports about the intestinal enteropathy in PHO patients. CEAS accompanied with $\mathrm{PHO}$ were previously reported [1416]. Since $S L C O 2 A 1$ is shared with $\mathrm{PHO}$, the major clinical manifestations of $\mathrm{PHO}$, such as digital clubbing, periostosis, pachydermia were commonly observed in CEAS [5]. However, the PHO was more common observed in male while the CEAS was dominant in female. The relationship between CEAS and PHO are not clear. Our patient reported here didn't show any typical features of $\mathrm{PHO}$ so far. 
In conclusion, patients with nonspecific small intestinal ulcers with intractable anemia or hypoproteinemia should suspect CEAS. Although CEAS was rarely reported outside Japanese population, PHO was constantly reported. It may be under estimated in other population.

\section{Abbreviations}

CEAS: Chronic enteropathy associated with SLCO2A1; OGIB: Obscure gastrointestinal bleeding; EEN: Exclusive enteral nutrition; MRE: Magnetic resonance enterography; PHO: Primary hypertrophic osteoarthropathy

\section{Acknowledgements}

None.

\section{Author contributions}

YF participated in the coordination and interpretation of data and wrote the manuscript. JC participated in the study design and helped draft the manuscript. YL and YF collected the clinical data of the patients and interpreted the results of molecular analysis. WG performed the immunohistochemical analysis. All authors read and approved the final manuscript.

\section{Funding}

This research is supported by the Natural Science Foundation of Zhejiang Province, China (LQ19H030010). The funder had no role in study design, data collection and analysis, decision to publish, or preparation of the manuscript.

\section{Availability of data and materials}

There is no more case-specific data that could be shared.

\section{Ethics approval and consent to participate}

This study was approved by the Ethics Committee of the Children's Hospital of Zhejiang University School of Medicine.

\section{Consent for publication}

Written informed consent was obtained from the parents of the patient for the publication of the case report.

\section{Competing interests}

The authors declare that they have no competing interests.

\section{Author details}

'Department of Gastroenterology, The Children's Hospital, Zhejiang University School of Medicine, National Clinical Research Center for Child Health, 3333 Bin Sheng RoadZhejiang Province, Hangzhou 310052, China. ${ }^{2}$ Department of Pathology, The Children's Hospital, Zhejiang University School of Medicine, National Clinical Research Center for Child Health, Hangzhou, China.

Received: 14 May 2020 Accepted: 8 September 2020 Published online: 17 September 2020

\section{References}

1. Raju GS, Gerson L, Das A, Lewis B, American Gastroenterological A. American Gastroenterological Association (AGA) Institute technical review on obscure gastrointestinal bleeding. Gastroenterology. 2007;133(5):1697717

2. Umeno J, Hisamatsu T, Esaki M, Hirano A, Kubokura N, Asano K, Kochi S, Yanai S, Fuyuno Y, Shimamura K, et al. A Hereditary Enteropathy Caused by Mutations in the SLCO2A1 Gene, Encoding a Prostaglandin Transporter. PLoS Genet. 2015;11(11):e1005581.

3. Sun X, Hosoe N, Miyanaga R, Kimura K, Mizuno S, Takabayashi K, Naganuma $M$, Niizeki $H$, Seki A, Ogata $H$, et al. A male Korean who was diagnosed with chronic enteropathy associated with SLCO2A1 (CEAS): case report with literature review. BMJ Open Gastroenterol. 2018;5(1):e000223.

4. Hu P, He H, Dai N, Zhang S, Deng L. Chronic enteropathy associated with SLCO2A1 gene: A case report and literature review. Clin Res Hepatol Gastroenterol. 2019;43(5):e68-72.
5. Umeno J, Esaki M, Hirano A, Fuyuno Y, Ohmiya N, Yasukawa S, Hirai F, Kochi S, Kurahara K, Yanai S, et al. Clinical features of chronic enteropathy associated with SLCO2A1 gene: a new entity clinically distinct from Crohn's disease. J Gastroenterol. 2018;53(8):907-15.

6. Uchida K, Nakajima A, Ushijima K, Ida S, Seki Y, Kakuta F, Abukawa D, Tsukahara H, Maisawa SI, Inoue M, et al. Pediatric-onset Chronic Nonspecific Multiple Ulcers of Small Intestine: A Nationwide Survey and Genetic Study in Japan. J Pediatr Gastroenterol Nutr. 2017;64(4):565-8.

7. Hosoe N, Ohmiya N, Hirai F, Umeno J, Esaki M, Yamagami H, Onodera K Bamba S, Imaeda H, Yanai S, et al. Chronic Enteropathy Associated With SLCO2A1 Gene [CEAS]-Characterisation of an Enteric Disorder to be Considered in the Differential Diagnosis of Crohn's Disease. J Crohns Colitis. 2017:11(10):1277-81.

8. Yanai S, Yamaguchi S, Nakamura S, Kawasaki K, Toya Y, Yamada N, Eizuka M, Uesugi N, Umeno J, Esaki M, et al. Distinction between Chronic Enteropathy Associated with the SLCO2A1 Gene and Crohn's Disease. Gut Liver. 2019; 13(1):62-6.

9. Busch J, Frank V, Bachmann N, Otsuka A, Oji V, Metze D, Shah K, Danda S, Watzer B, Traupe $\mathrm{H}$, et al. Mutations in the prostaglandin transporter SLCO2A1 cause primary hypertrophic osteoarthropathy with digital clubbing. J Invest Dermatol. 2012;132(10):2473-6.

10. Zhang Z, He JW, Fu WZ, Zhang CQ, Zhang ZL. Mutations in the SLCO2A1 gene and primary hypertrophic osteoarthropathy: a clinical and biochemical characterization. J Clin Endocrinol Metab. 2013;98(5):E923-933.

11. Zhang Z, He JW, Fu WZ, Zhang CQ, Zhang ZL. Two novel mutations in the SLCO2A1 gene in a Chinese patient with primary hypertrophic osteoarthropathy. Gene. 2014;534(2):421-3.

12. Lee S, Park SY, Kwon HJ, Lee $\mathrm{CH}$, Kim OH, Rhee Y. Identification of the Mutations in the Prostaglandin Transporter Gene, SLCO2A1 and Clinical Characterization in Korean Patients with Pachydermoperiostosis. J Korean Med Sci. 2016:31(5):735-42

13. Li SS, He JW, Fu WZ, Liu YJ, Hu YQ, Zhang ZL. Clinical, Biochemical, and Genetic Features of 41 Han Chinese Families With Primary Hypertrophic Osteoarthropathy, and Their Therapeutic Response to Etoricoxib: Results From a Six-Month Prospective Clinical Intervention. J Bone Miner Res. 2017; 32(8):1659-66.

14. Compton RF, Sandborn WJ, Yang H, Lindor NM, Tremaine WJ, Davis MD, Khalil AA, Tountas NA, Tyan DB, Landers CJ, et al. A new syndrome of Crohn's disease and pachydermoperiostosis in a family. Gastroenterology. 1997;112(1):241-9.

15. Shim YW, Suh JS: Primary hypertrophic osteoarthropathy accompanied by Crohn's disease: a case report. Yonsei Med J 1997, 38(5):319-322.

16. McAllister C, McNulty JG, Fielding JF. Is hypertrophic osteoarthropathy really so rare in regional enteritis? J Clin Gastroenterol. 1986;8(5):562-6.

\section{Publisher's Note}

Springer Nature remains neutral with regard to jurisdictional claims in published maps and institutional affiliations.
Ready to submit your research? Choose BMC and benefit from:

- fast, convenient online submission

- thorough peer review by experienced researchers in your field

- rapid publication on acceptance

- support for research data, including large and complex data types

- gold Open Access which fosters wider collaboration and increased citations

- maximum visibility for your research: over $100 \mathrm{M}$ website views per year

At BMC, research is always in progress.

Learn more biomedcentral.com/submission 